Check for updates

Cite this: RSC Adv., 2018, 8, 7679

Received 8th January 2018

Accepted 12th February 2018

DOI: $10.1039 / c 8 r a 00190 a$

rsc.li/rsc-advances

\section{Structure, luminescence and temperature sensing in rare earth doped glass ceramics containing $\mathrm{NaY}\left(\mathrm{WO}_{4}\right)_{2}$ nanocrystals}

\author{
Zeshang Zou, Ting Wu, Hao Lu, Yuyuan Tu, Shilong Zhao, (D)* Shichao Xie, Fang Han \\ and Shiqing $\mathrm{Xu}$
}

Novel rare earth doped glass ceramics containing $\mathrm{NaY}\left(\mathrm{WO}_{4}\right)_{2}$ nanocrystals were fabricated for the first time. The appearance of sharp diffraction peaks and well-resolved lattice fringes certifies the precipitation of $\mathrm{NaY}\left(\mathrm{WO}_{4}\right)_{2}$ nanocrystals with high crystallinity. After the crystallization process, significant changes in the photoluminescence emission spectra and fluorescence lifetime of $\mathrm{Sm}^{3+}$ ions are observed, which are ascribable to the enrichment of $\mathrm{Sm}^{3+}$ ions in the highly disordered $\mathrm{NaY}\left(\mathrm{WO}_{4}\right)_{2}$ nanocrystals. Under $980 \mathrm{~nm}$ excitation, characteristic green and red upconversion emission signals were detected and the enhanced upconversion luminescence of $\mathrm{Er}^{3+}$ ions in the glass ceramics was attributable to the incorporation into the low energy phonon $\mathrm{NaY}\left(\mathrm{WO}_{4}\right)_{2}$ nanocrystals. Based on the dependence of upconversion intensity on the excitation power, the upconversion mechanism of $\mathrm{Er}^{3+}-\mathrm{Yb}^{3+}$ ions was proposed. The temperature-dependent fluorescence intensity ratio (FIR) of the thermally-coupled ${ }^{2} \mathrm{H}_{11 / 2}$ and ${ }^{4} S_{3 / 2}$ energy levels was determined at a low power density of $0.4125 \mathrm{~W} \mathrm{~cm}^{-2}$. The maximum temperature sensitivity is $146 \times 10^{-4} \mathrm{~K}^{-1}$ at $523 \mathrm{~K}$, which is mainly attributed to the highly disordered structure of $\mathrm{NaY}\left(\mathrm{WO}_{4}\right)_{2}$ nanocrystals and exhibits promising potential for optical temperature sensors.

\section{Introduction}

In recent years, upconversion luminescence of active ions has attracted wide interest owing to its promising applications in bioimaging, solar cells, white LEDs and temperature sensing..$^{1-4}$ Especially, temperature sensors based on the FIR technique have garnered great attention due to their negligible electromagnetic interference, simple data processing and high sensitivity. ${ }^{4-7}$ Currently, the research of high-performance temperature sensors mainly focuses on the optimization of active ions and host matrix. $\mathrm{Er}^{3+}$ ion is the most extensively investigated because of its intense upconversion luminescence and appropriate bandgap (around $800 \mathrm{~cm}^{-1}$ ) between ${ }^{2} \mathrm{H}_{11 / 2}$ and ${ }^{4} S_{3 / 2}$ energy levels, which exactly fall in the thermallycoupled energy range $\left(200-2000 \mathrm{~cm}^{-1}\right) .^{8}$ In order to obtain stronger upconversion luminescence, $\mathrm{Yb}^{3+}$ is usually utilized as the preferred sensitizer for $\mathrm{Er}^{3+}$ due to its high absorption crosssection at $980 \mathrm{~nm}$ and efficient $\mathrm{Yb}^{3+} \rightarrow \mathrm{Er}^{3+}$ energy transfer efficiency. ${ }^{9}$ It is well known that the phonon energy and crystal structure of host matrix have an important role on the upconversion luminescence efficiency. A low phonon energy is very beneficial to enhance the upconversion efficiency of activators as a result of the reduction in the multi-phonon relaxation rate. ${ }^{10}$ Hexagonal $\mathrm{NaYF}_{4}$ is regarded as the most efficient

College of Materials Science and Engineering, China Jiliang University, Hangzhou 310018, P. R. China.E-mail: Shilong_zhao@hotmail.com; sxucjlu@hotmail.com upconversion host matrix due to its low phonon energy and multisite characteristic. ${ }^{11}$ The temperature sensing performance of $\mathrm{Er}^{3+}$ ions in hexagonal $\mathrm{NaYF}_{4}$ was studied and the maximum temperature sensitivity was $37 \times 10^{-4} \mathrm{~K}^{-1}$ at $508 \mathrm{~K}^{12}$ By now, various host materials have been investigated for optical thermometry, however, the influence of crystal structure on the temperature sensitivity is rarely investigated..$^{13}$ Recently, three Judd-Ofelt parameters ${ }^{14,15}$ of $\mathrm{Er}^{3+}$ ions were calculated and used to analyze the role of host matrix from oxyfluoride glass to cubic $\mathrm{NaYF}_{4}$ glass ceramic on the temperature sensitivity. It was found that the maximum temperature sensitivity of $\mathrm{Er}^{3+}$ ions in the precursor glass $\left(66 \times 10^{-4} \mathrm{~K}^{-1}\right.$ at $\left.570 \mathrm{~K}\right)$ is twice more than the value in the cubic $\mathrm{NaYF}_{4}$ glass ceramic $\left(24 \times 10^{-4} \mathrm{~K}^{-1}\right.$ at $\left.540 \mathrm{~K}\right)$. Based on the structural change during the temperature-induced crystallization process, it is concluded that the more disordered the local environment of active ions, the better FIR and temperature sensing sensitivity. Thus, oxide glass is regarded as an ideal host matrix doped with $\mathrm{Er}^{3+}$ ions for optical thermometry due to its highly disordered local symmetry surroundings. ${ }^{16}$ Unfortunately, a low upconversion efficiency of active ions can only be obtained in oxide glasses due to their high phonon energy.

Rare earth doped double tungstate/molybdate phosphors have been extensively investigated due to their structural versatility, good thermal stability and low phonon energy. Recently, intense green upconversion luminescence was observed in the $\mathrm{Er}^{3+} / \mathrm{Yb}^{3+}$ codoped $\mathrm{NaY}\left(\mathrm{WO}_{4}\right)_{2}$ phosphors and its temperature sensing behaviour was analysed by the FIR 
technique. ${ }^{17}$ A maximum temperature sensing sensitivity about $112 \times 10^{-4} \mathrm{~K}^{-1}$ was obtained at $515 \mathrm{~K}$, which was about three times larger than that in the $\mathrm{NaYF}_{4}$ nanocrystals ${ }^{12}$ and exhibited promising potential for application on optical thermometry. Moreover, in order to assemble a practical optical fiber temperature sensing probe, the phosphor is usually adhered to the end face of optical fiber by organic resin (epoxy resin or silicone). Therefore, the operating temperature range, longterm reliability and lifetime of optical fiber temperature sensor are reduced dramatically. Glass can be easily drawn into glass fiber and conveniently spliced to standard silica fiber. The combination of oxide glass and tungstate/molybdate phosphor is expected to improve the performance of temperature sensors. Therefore, the key problem is to develop an appropriate glass composition, in which tungstate/molybdate nanocrystals could be successfully separated from the precursor glass and intense upconversion emission could be achieved.

Here, transparent glass ceramics containing $\mathrm{NaY}\left(\mathrm{WO}_{4}\right)_{2}$ nanocrystals have been successfully prepared by the optimization of glass composition and thermal treatment condition. $\mathrm{Sm}^{3+}$ ion usually acts as a spectroscopic probe to distinguish the local site symmetry around active ions in the host matrix. The spectral analysis of $\mathrm{Sm}^{3+}$ ions in the precursor glass and glass ceramics containing $\mathrm{NaY}\left(\mathrm{WO}_{4}\right)_{2}$ nanocrystals has been carried out and used to estimate their potential performance for optical temperature sensing. Successively, the temperature dependent upconversion emission spectra in $\mathrm{Er}^{3+} / \mathrm{Yb}^{3+}$ codoped glass and glass ceramics were systematically investigated. According to FIR technique, the influence of host matrix on the temperature sensitivity was discussed in details.

\section{Experimental}

\section{Sample preparation}

The glass samples were fabricated with molar composition of $62 \mathrm{SiO}_{2}-16 \mathrm{~B}_{2} \mathrm{O}_{3}-11 \mathrm{Na}_{2} \mathrm{O}-7 \mathrm{ZnO}-3 \mathrm{WO}_{3}-0.9 \mathrm{Y}_{2} \mathrm{O}_{3}-0.1 \mathrm{Sm}_{2} \mathrm{O}_{3}$ and $62 \mathrm{SiO}_{2}-16 \mathrm{~B}_{2} \mathrm{O}_{3}-11 \mathrm{Na}_{2} \mathrm{O}-7 \mathrm{ZnO}-3 \mathrm{WO}_{3}-0.75 \mathrm{Y}_{2} \mathrm{O}_{3}-0.05 \mathrm{Er}_{2} \mathrm{O}_{3}-0.2$ $\mathrm{Yb}_{2} \mathrm{O}_{3}$. Firstly, high purity raw materials $\mathrm{SiO}_{2}, \mathrm{H}_{3} \mathrm{BO}_{3}, \mathrm{Na}_{2} \mathrm{CO}_{3}$, $\mathrm{ZnO}, \mathrm{WO}_{3}, \mathrm{Y}_{2} \mathrm{O}_{3}, \mathrm{Sm}_{2} \mathrm{O}_{3}, \mathrm{Er}_{2} \mathrm{O}_{3}$ and $\mathrm{Yb}_{2} \mathrm{O}_{3}$ were weighed accurately and mixed thoroughly. Then, the well-mixed raw materials were put into a covered $\mathrm{Al}_{2} \mathrm{O}_{3}$ crucible and were transferred to an electric furnace preheated to $1500{ }^{\circ} \mathrm{C}$ for about $30 \mathrm{~min}$. Finally, the glass melt was quenched into a cold stainless-steel plate and rapidly transferred to a pre-heated muffle furnace. Transparent precursor glasses (PG) were obtained. PG samples were cut into small pieces and heat-treated at $610^{\circ} \mathrm{C}, 630{ }^{\circ} \mathrm{C}$ and $650{ }^{\circ} \mathrm{C}$ for $2 \mathrm{~h}$, respectively. The obtained glass ceramics were named as GC-610, GC-630 and GC-650, respectively. All the samples were polished for further characterization. The final thickness of PG and glass ceramics is $1.5 \mathrm{~mm}$.

\section{Characterization}

The crystallized phase before and after thermal treatment was identified via X-ray diffraction (XRD) measurement (Bruker D2 PHASER Diffractometer), with $\mathrm{Cu}-\mathrm{K}_{\alpha}$ radiation in $2 \theta$ range from $10^{\circ}$ to $80^{\circ}$ with a step length $0.02^{\circ}$. The microstructure of
GC-650 was examined on a transmission electron microscope (TEM, Philips-FEI-Tecnai G2 F30). Excitation and emission spectra of $\mathrm{Sm}^{3+}$ ions at room temperature were recorded on a fluorescence spectrophotometer equipped with a Hamamatsu R928 photomultiplier tube (Horiba J-Y Fluorolog-3). $450 \mathrm{~W}$ xenon lamp was used as the light source. The luminescence decay curves of ${ }^{4} \mathrm{G}_{5 / 2}$ levels of $\mathrm{Sm}^{3+}$ ions were recorded on the above apparatus excited at $370 \mathrm{~nm}$. Upconversion luminescence $\mathrm{Er}^{3+} / \mathrm{Yb}^{3+}$ co-doped samples were also performed on the same spectrophotometer and a $980 \mathrm{~nm}$ laser diode module (MDL-III980, China) was used to excite the samples. The output spot size of $980 \mathrm{~nm}$ laser was $4 \times 6 \mathrm{~mm}^{2}$. In order to study the temperature-dependent upconversion luminescence of $\mathrm{Er}^{3+}$, the temperature controller (TAP-02) was used to heat the sample from 298 to $573 \mathrm{~K}$ and its temperature accuracy is $0.1 \mathrm{~K}$.

\section{Results and discussion}

\section{Microstructure analysis}

The XRD profiles of $\mathrm{PG}$ and glass ceramics are presented in Fig. 1(a). In the PG, no obvious diffraction peaks are detected in
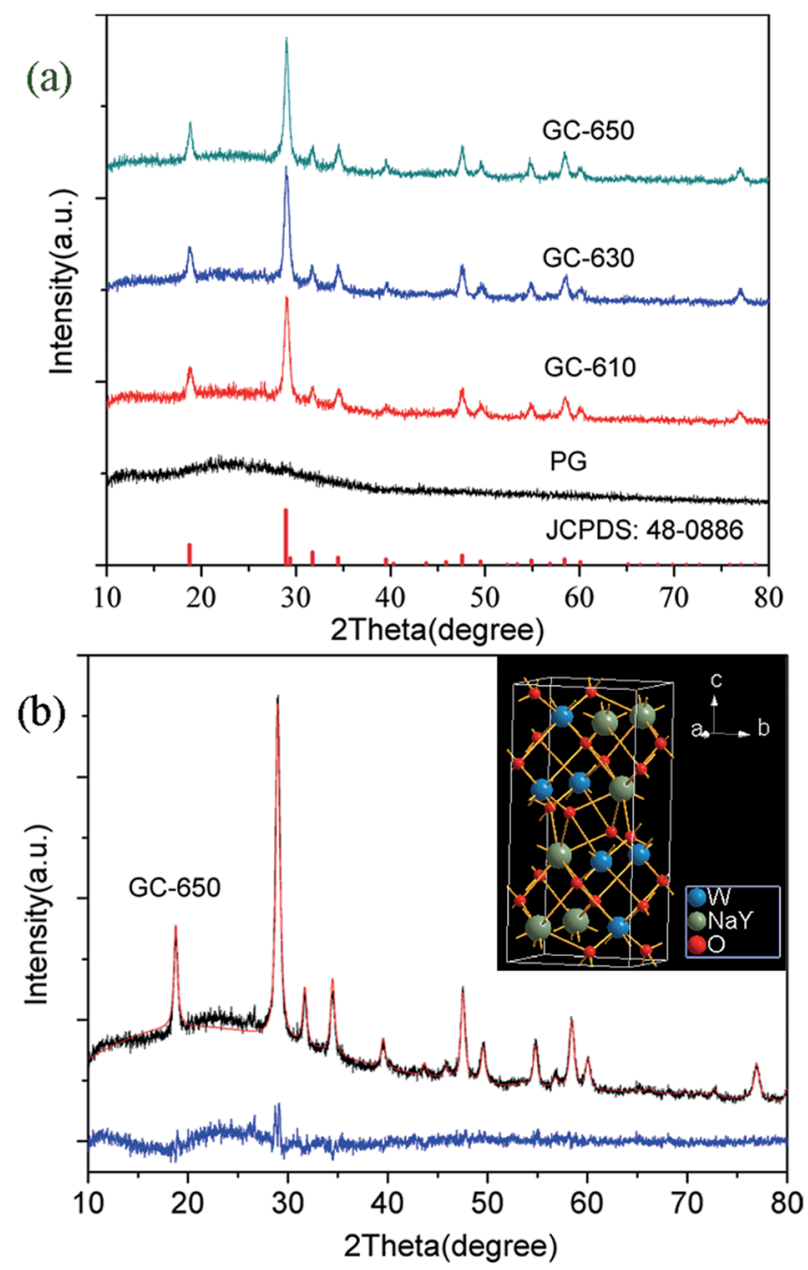

Fig. 1 (a) XRD profiles of PG and glass ceramics; (b) Rietveld XRD refinement of GC-650, the inset shows the crystal structure of $\mathrm{NaY}\left(\mathrm{WO}_{4}\right)_{2}$. 
the range of $10-80^{\circ}$, indicative of the amorphous feature of glass matrix. When the samples were thermal-treated at 610,630 and $650{ }^{\circ} \mathrm{C}$ for $2 \mathrm{~h}$, intense diffraction peaks are observed and easily assigned to pure tetragonal $\mathrm{NaY}\left(\mathrm{WO}_{4}\right)_{2}$ (JCPDS No 48-0886). The full width at half-maximum (FWHM) of diffraction peaks becomes narrower with the increase of thermal treatment temperature, indicating the gradual growth of $\mathrm{NaY}\left(\mathrm{WO}_{4}\right)_{2}$ phase. The average crystalline size of $\mathrm{NaY}\left(\mathrm{WO}_{4}\right)_{2}$ nanocrystals could be calculated based on the Scherrer formula, ${ }^{18}$

$$
D=\frac{0.9 \lambda}{\mu \cos \theta}
$$

in which $\lambda$ is X-ray wavelength, $\mu$ is FWHM of diffraction peaks, and $\theta$ is diffraction angle. The average crystalline sizes were $15.0 \mathrm{~nm}, 17.8 \mathrm{~nm}$ and $20.9 \mathrm{~nm}$ for GC-610, GC-630 and GC-650, respectively.

The Rietveld XRD refinement of GC-650 was carried out by using TOPAS software. The initial structural models was $\mathrm{NaY}_{0.95} \mathrm{Yb}_{0.05}\left(\mathrm{WO}_{4}\right)_{2} \cdot{ }^{19}$ Fig. 1(b) show the observed and calculated diffraction peaks as well as the difference of GC-650, which are nearly identical and suggests that GC-650 has a pure tetragonal phase. The fitting reliability parameters of $R_{\text {exp }}, R_{\mathrm{wp}}, R_{\mathrm{p}}$, and GOF are 3.94, 5.90, 4.82 and 1.5, respectively. The inset of Fig. 1(b) represents the crystal structure of $\mathrm{NaY}\left(\mathrm{WO}_{4}\right)_{2}$ drawn by Diamond software. The crystal has a high structural disorder. Especially, $\mathrm{Na}$ and $\mathrm{Y}$ occupy the same sites in the structure randomly and link with eight oxygen atoms, forming $\mathrm{NaO}_{8}$ and $\mathrm{YO}_{8}$ edge-sharing polyhedral with $\mathrm{S}_{4}$ site symmetry, while $\mathrm{W}^{6+}$ ions are coordinated with four oxygen atoms. ${ }^{20}$

Fig. 2(a) gives the dark field TEM image of $\mathrm{NaY}\left(\mathrm{WO}_{4}\right)_{2}$ nanocrystals in the GC-650. One can observe plenty of dark and nearly spherical nanoparticles, corresponding to the precipitated $\mathrm{NaY}\left(\mathrm{WO}_{4}\right)_{2}$ nanocrystals, while the grey background is amorphous glass phase. The HRTEM image of an individual $\mathrm{NaY}\left(\mathrm{WO}_{4}\right)_{2}$ nanocrystal shows the well-resolved lattice fringes, which suggests that the precipitated $\mathrm{NaY}\left(\mathrm{WO}_{4}\right)_{2}$ nanocrystal possess high crystallinity. The measured interplanar distance is $0.309 \mathrm{~nm}$, which can be well-indexed as the $d$-spacing value of

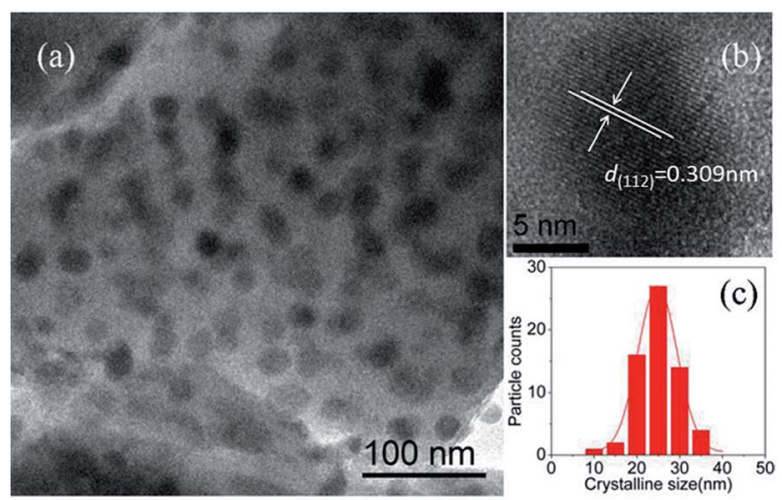

Fig. 2 (a) TEM image of $\mathrm{NaY}\left(\mathrm{WO}_{4}\right)_{2}$ nanocrystals in the GC-650; (b) HRTEM micrograph of an individual $\mathrm{NaY}\left(\mathrm{WO}_{4}\right)_{2}$ nanocrystal; (c) crystalline size distribution of $\mathrm{NaY}\left(\mathrm{WO}_{4}\right)_{2}$ nanocrystals in the GC-650.
(112) crystal plane of $\mathrm{NaY}\left(\mathrm{WO}_{4}\right)_{2}$ crystal $\left(d_{(112)}=0.308 \mathrm{~nm}\right)$. The crystalline size of $\mathrm{NaY}\left(\mathrm{WO}_{4}\right)_{2}$ is around $25 \mathrm{~nm}$ with a narrow size distribution, which is slightly larger than the value $(20.9 \mathrm{~nm})$ calculated from XRD data. The same phenomenon was reported in the $\mathrm{PbF}_{2}$ glass ceramics, which was due to the broadening of diffraction peaks and suggested the presence of disorder of the precipitated nanocrystals. ${ }^{21}$

\section{Photoluminescence and decay lifetimes of $\mathrm{Sm}^{3+}$ ions}

Fig. 3 shows the photoluminescence spectra of $\mathrm{Sm}^{3+}$ ions in the glass samples before and after thermal treatment. The excitation wavelength is $404 \mathrm{~nm}$. Some strong emission bands at around 566, 602, 648 and $706 \mathrm{~nm}$ are observed, which correspond to the transitions from ${ }^{4} \mathrm{G}_{5 / 2}$ energy level to ${ }^{6} \mathrm{H}_{5 / 2},{ }^{6} \mathrm{H}_{7 / 2}$, ${ }^{6} \mathrm{H}_{9 / 2}$ and ${ }^{6} \mathrm{H}_{11 / 2}$ energy levels of $\mathrm{Sm}^{3+}$ ions, respectively. ${ }^{22}$ The whole emission intensity of $\mathrm{Sm}^{3+}$ ions after thermal treatment is greatly enhanced with the increase of thermal treatment temperature and obvious Stark splitting appear at $602 \mathrm{~nm}$, which is attributed to the segregation of $\mathrm{Sm}^{3+}$ ions into the low phonon energy $\mathrm{NaY}\left(\mathrm{WO}_{4}\right)_{2}$ nanocrystals by occupying the sites of $\mathrm{Y}^{3+}$ ions. ${ }^{23}$ It is notable that the strongest photoluminescence
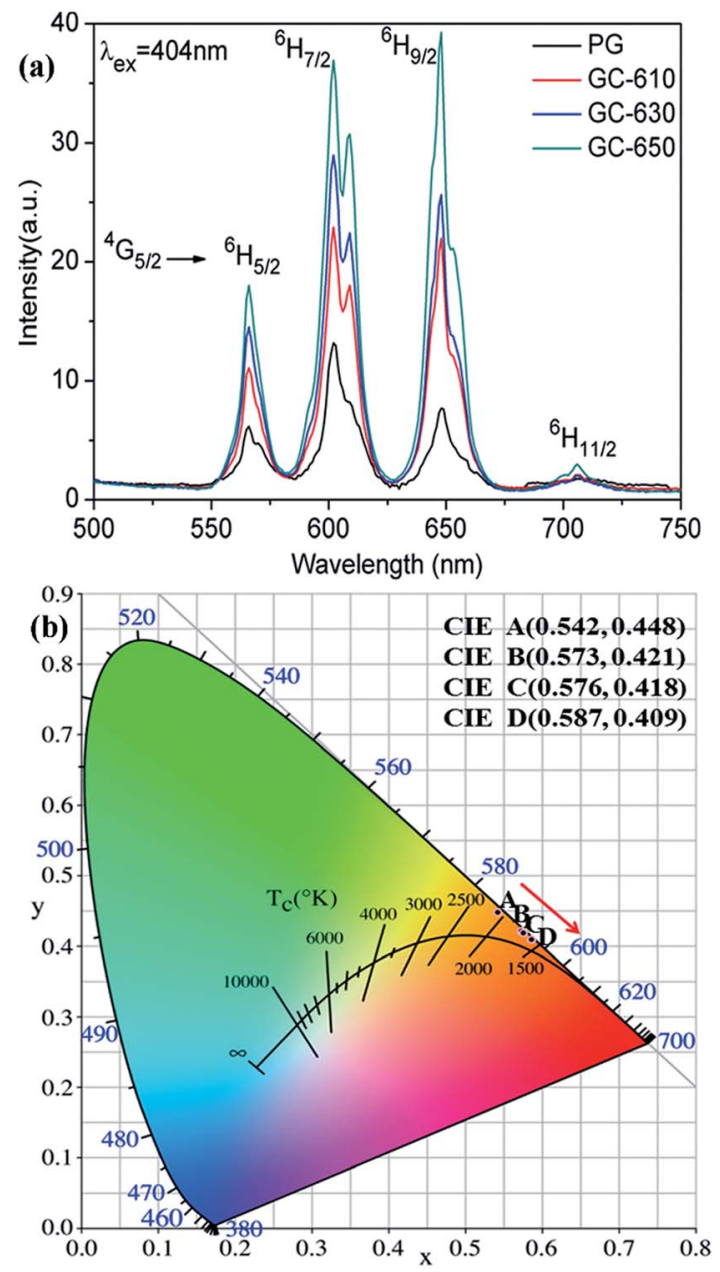

Fig. 3 (a) Photoluminescence spectra of $\mathrm{Sm}^{3+}$ ions (excited at $404 \mathrm{~nm}$ ); (b) ClE coordinates of Sm ${ }^{3+}$ doped PG, GC-610, 6C-630 and GC-650, which are labelled as A, B, C, and D, respectively. 
emission band in the PG originates from ${ }^{4} \mathrm{G}_{5 / 2} \rightarrow{ }^{6} \mathrm{H}_{7 / 2}$ transition at $602 \mathrm{~nm}$, while the strongest photoluminescence emission band in the GC-650 becomes ${ }^{4} \mathrm{G}_{5 / 2} \rightarrow{ }^{6} \mathrm{H}_{9 / 2}$ transition at $648 \mathrm{~nm}$, which is completely on the contrary to the luminescent behaviour of $\mathrm{Sm}^{3+}$ ions in $\mathrm{YF}_{3}$ glass ceramics. ${ }^{24} \mathrm{Sm}^{3+}$ ions are very sensitive to the subtle change of external environment and acts as a spectroscopic probe to investigate the local site symmetry around active ions in the host matrix. According to the selection rules of electronic transitions, ${ }^{25}{ }^{4} \mathrm{G}_{5 / 2} \rightarrow{ }^{6} \mathrm{H}_{5 / 2}$ transition belongs to magnetic dipole transition due to $\Delta J=0$, which is nearly independent of the local environmental change around $\mathrm{Sm}^{3+}$ ions, while ${ }^{4} \mathrm{G}_{5 / 2} \rightarrow{ }^{6} \mathrm{H}_{9 / 2}$ transition is electric transition because of $\Delta J=2$ and which is highly sensitive to external environmental change. In general, the intensity ratio $\beta$ between ${ }^{4} \mathrm{G}_{5 / 2} \rightarrow{ }^{6} \mathrm{H}_{9 / 2}$ and ${ }^{4} \mathrm{G}_{5 / 2} \rightarrow{ }^{6} \mathrm{H}_{5 / 2}$ transitions is used to evaluate the local site symmetry around $\mathrm{Sm}^{3+}$ ions. When $\mathrm{Sm}^{3+}$ ions are situated in the surroundings close to inversion symmetry, ${ }^{4} \mathrm{G}_{5 / 2} \rightarrow{ }^{6} \mathrm{H}_{5 / 2}$ will be stronger, while in the surroundings far away from inversion symmetry, the ${ }^{4} \mathrm{G}_{5 / 2} \rightarrow$ ${ }^{6} \mathrm{H}_{9 / 2}$ will be predominant. The calculated $\beta$ values in the PG, GC-610, GC-630 and GC-650 are 1.25, 1.76, 1.98 and 2.18, respectively. The gradual increase of $\beta$ value demonstrates that $\mathrm{Sm}^{3+}$ ions are far away from inversion symmetry and enter into a more disordered surrounding after thermal treatment process, which favours the strengthening of photoluminescence intensity for the hypersensitive transitions and is very beneficial to enhance the temperature sensing sensitivity. ${ }^{26,27}$

Due to the relative photoluminescence intensity of $\mathrm{Sm}^{3+}$ ions change greatly after thermal treatment, the Commission Internationale de I'Eclairage (CIE) chromaticity coordinates were calculated in order to evaluate the colorimetric performance calculated from the emission spectra. The calculated chromaticity coordinates were A $(0.542,0.448), \mathrm{B}(0.573,0.421), \mathrm{C}$ $(0.576,0.418)$ and D $(0.587,0.409)$ for the PG, GC-610, GC-630 and GC-650, respectively, which were labelled in the Fig. 3(b). It is found that the colour changes from yellow orange to reddish orange after thermal treatment, which indicates that glass ceramic doped $\mathrm{Sm}^{3+}$ ions could be served as alternative red phosphors in the white LED application.

The luminescence decay curves of $\mathrm{Sm}^{3+}$ ions in different samples are investigated and presented in the Fig. 4 . The excitation wavelength is $370 \mathrm{~m}$ and the emission wavelength is $602 \mathrm{~nm}$. All the decay curves are well described with a twoexponential equation, ${ }^{28}$

$$
I=A_{1} \exp \left(-\frac{t}{\tau_{1}}\right)+A_{2} \exp \left(-\frac{t}{\tau_{2}}\right)
$$

in which $I$ is the emission intensity, $A_{1}$ and $A_{2}$ are the fitting parameters, $\tau_{1}$ and $\tau_{2}$ are the slow and rapid lifetimes for exponential components, respectively. The average fluorescence lifetime can be calculated as:

$$
\tau=\frac{A_{1} \tau_{1}^{2}+A_{2} \tau_{2}^{2}}{A_{1} \tau_{1}+A_{2} \tau_{2}}
$$

The fitting average fluorescence lifetime of $\mathrm{Sm}^{3+}$ ions are 2.00, 2.13, 2.32 and 2.64 ms for PG, GC-610, GC-630 and GC-650,

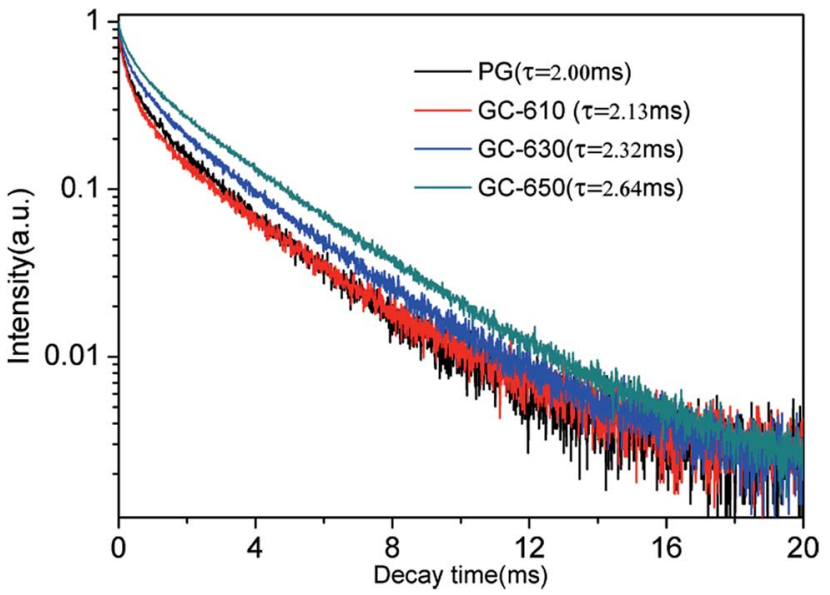

Fig. 4 Luminescence decay curves of $\mathrm{Sm}^{3+}$ ions in different samples.

respectively. The gradual increase of fluorescence lifetime of $\mathrm{Sm}^{3+}$ ions in the glass ceramics can be ascribed to that much more $\mathrm{Sm}^{3+}$ ions partition into the low phonon energy $\mathrm{NaY}\left(\mathrm{WO}_{4}\right)_{2}$ nanocrystals and the non-radiative transition rate of $\mathrm{Sm}^{3+}$ ions reduces.

\section{Upconversion luminescence and mechanism of $\mathrm{Er}^{3+}$ ions}

Fig. 5(a) shows the upconversion emission spectra of $\mathrm{Er}^{3+} / \mathrm{Yb}^{3+}$ ions in different samples at room temperature. The excitation wavelength is $980 \mathrm{~nm}$ and its excitation power is $99 \mathrm{~mW}$. Thus, the power density is $0.4125 \mathrm{~W} \mathrm{~cm}^{-2}$, which is enough low and the heating effect caused by $980 \mathrm{~nm}$ excitation may be ignored. ${ }^{29}$ Strong green upconversion emission as well as weak red upconversion emission are recorded, which are originated from the ${ }^{2} \mathrm{H}_{11 / 2} \rightarrow{ }^{4} \mathrm{I}_{15 / 2}(533 \mathrm{~nm}),{ }^{4} \mathrm{~S}_{3 / 2} \rightarrow{ }^{4} \mathrm{I}_{15 / 2}(555 \mathrm{~nm})$ and ${ }^{4} \mathrm{~F}_{9 / 2} \rightarrow$ ${ }^{4} \mathrm{I}_{15 / 2}(658 \mathrm{~nm})$ transitions of $\mathrm{Er}^{3+}$ ions, respectively. With the increase of thermal treatment temperature, the upconversion intensity is significantly raised and its intensity in GC-650 is 60 times higher than that of PG. The red-to-green emission ratios are $0.263,0.242,0.138$ and 0.117 for the PG and GC-610, GC-630 and GC-650, respectively. The decrease of red-to-green emission ratio is mainly attributed to the gradual incorporation of $\mathrm{Er}^{3+}$ and $\mathrm{Yb}^{3+}$ into the low-phonon-energy $\mathrm{NaY}\left(\mathrm{WO}_{4}\right)_{2}$ nanocrystals, which effectively reduce the populations of ${ }^{4} \mathrm{~F}_{9 / 2}$ energy level through the non-radiative ${ }^{4} \mathrm{~S}_{3 / 2} \rightarrow{ }^{4} \mathrm{~F}_{9 / 2}$ transition. Furthermore, intense Stark splitting of $\mathrm{Er}^{3+}$ ions due to high crystal field effect also verify the above viewpoint. In order to analyze upconversion mechanism of $\mathrm{Er}^{3+}$ ions, the double logarithmic curves of upconversion intensity as a function of excitation power is determined and shown in the inset of Fig. 5(a). For an unsaturated process, the correlation of upconversion intensity $I$ and excitation power $P$ satisfy the following formula, ${ }^{30} I \propto P^{n}$, in which $n$ is the number of the pump photon absorbed in the upconversion process for one visible photon emitted. Thus, the $n$ values are equal to the slopes in the inset of Fig. 5(a) and are 1.95, 1.89 and 1.83 for $533 \mathrm{~nm}, 555 \mathrm{~nm}$, and $658 \mathrm{~nm}$, respectively. These values demonstrate that a double-photon absorption process is responsible for the populations on the ${ }^{2} \mathrm{H}_{11 / 2},{ }^{4} \mathrm{~S}_{3 / 2}$ and ${ }^{4} \mathrm{~F}_{9 / 2}$ energy levels of $\mathrm{Er}^{3+}$ ions. Based on the above data, the 

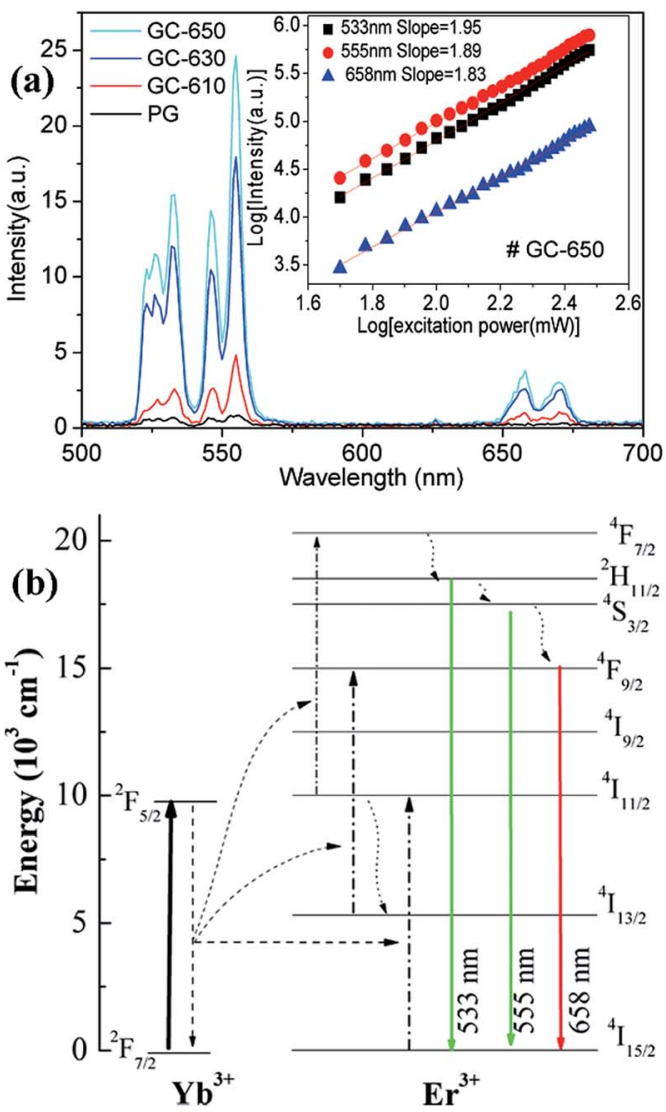

Fig. 5 (a) Upconversion emission spectra of $\mathrm{Er}^{3+} / \mathrm{Yb}^{3+}$ ions in different samples under $980 \mathrm{~nm}$ excitation; (b) energy level diagram of $\mathrm{Er}^{3+}$ and $\mathrm{Yb}^{3+}$ and the proposed upconversion luminescence mechanisms $\mathrm{Er}^{3+}$ and $\mathrm{Yb}^{3+}$.

upconversion mechanism of $\mathrm{Er}^{3+}, \mathrm{Yb}^{3+}$ ions was proposed and plotted in the Fig. 5(b). Due to its wide absorption cross-section at $980 \mathrm{~nm}$ of $\mathrm{Yb}^{3+}$ ions, $980 \mathrm{~nm}$ light is mainly absorbed by $\mathrm{Yb}^{3+}$ and the latter efficiently transfers the energy to the adjacent $\mathrm{Er}^{3+}$ ions. ${ }^{21}$ Subsequently, $\mathrm{Er}^{3+}$ ions are excited to ${ }^{4} \mathrm{~F}_{7 / 2}$ energy level through absorbing double $980 \mathrm{~nm}$ photons from $\mathrm{Yb}^{3+}$ ions. Then, the ${ }^{2} \mathrm{H}_{11 / 2},{ }^{4} \mathrm{~S}_{3 / 2}$ and ${ }^{4} \mathrm{~F}_{9 / 2}$ energy levels are successively populated by the rapid non-radiative relaxation from ${ }^{4} \mathrm{~F}_{7 / 2}$ energy level, from which green and red upconversion emissions appear. Moreover, the population of ${ }^{4} \mathrm{~F}_{9 / 2}$ energy level may be also from the energy transfer process of ${ }^{4} \mathrm{I}_{13 / 2}$ energy level.

Temperature dependence upconversion luminescence of $\mathbf{E r}^{3+}$ ions and temperature sensing performance

In order to investigate the potential of $\mathrm{Er}^{3+} / \mathrm{Yb}^{3+}$ codoped glass ceramics containing $\mathrm{NaY}\left(\mathrm{WO}_{4}\right)_{2}$ nanocrystals for optical thermometry based on FIR technique, the dependence of green upconversion luminescence in GC-650 on the temperature was measured at the temperature range from 298 to $573 \mathrm{~K}$ and the change of the integrated upconversion intensity of ${ }^{2} \mathrm{H}_{11 / 2}\left(I_{\mathrm{H}}\right)$, ${ }^{4} \mathrm{~S}_{3 / 2}\left(I_{\mathrm{S}}\right)$ as well as ${ }^{2} \mathrm{H}_{11 / 2}+{ }^{4} \mathrm{~S}_{3 / 2}\left(I_{\mathrm{H}}+I_{\mathrm{S}}\right)$ of $\mathrm{Er}^{3+}$ ions versus temperature is shown in the Fig. 6(a). It is notable that the integrated upconversion intensity $I_{\mathrm{H}}$ of ${ }^{2} \mathrm{H}_{11 / 2} \rightarrow{ }^{4} \mathrm{I}_{15 / 2}$ transition first increase and then decrease slowly with the enhancement of environmental temperature. The maximum value of $I_{\mathrm{H}}$ occurs at $423 \mathrm{~K}$. On the contrary, the integrated upconversion intensity $I_{\mathrm{S}}$ of ${ }^{4} \mathrm{~S}_{3 / 2} \rightarrow{ }^{4} \mathrm{I}_{15 / 2}$ transition decreases dramatically, which results in the FIR of two energy levels $\left(I_{\mathrm{H}} / I_{\mathrm{S}}\right)$ rise from 0.81 to 4.49 . In general, when the temperature increases from 298 to $573 \mathrm{~K}$, the upconversion emission become weak due to thermal quenching effect. In our experiment, the whole green upconversion intensity $\left(I_{\mathrm{H}}+I_{\mathrm{S}}\right)$ reduces by $1 / 2$ and intense green emission can be observed at $573 \mathrm{~K}$. This is very beneficial to improve the accuracy of optical data. In order to better reveal the relative change of FIR, the green upconversion emissions were normalized to the intensity at $555 \mathrm{~nm}$ and shown in the Fig. 6(b). Clearly, the upconversion emission wavelength changes little, however, the FIR change significantly. Owing to the small bandgap between ${ }^{2} \mathrm{H}_{11 / 2}$ and ${ }^{4} \mathrm{~S}_{3 / 2}$, they are thermally coupled and ${ }^{2} \mathrm{H}_{11 / 2}$ energy level may be easily populated via thermal excitation from ${ }^{4} \mathrm{~S}_{3 / 2}$ energy level and achieve thermal equilibrium, which follows the Boltzmann distribution law. The FIR of upconversion emission is proportional to the ratio of the populations corresponding energy levels and is expressed as:

$$
\mathrm{FIR}=\frac{I_{\mathrm{H}}}{I_{\mathrm{S}}}=\frac{N\left({ }^{2} \mathrm{H}_{11 / 2}\right)}{N\left({ }^{4} S_{3 / 2}\right)}=C \exp \left(-\frac{\Delta E}{k T}\right)
$$

in which $I_{\mathrm{H}}$ and $I_{\mathrm{S}}$ are the integrated upconversion intensities for the ${ }^{2} \mathrm{H}_{11 / 2} \rightarrow{ }^{4} \mathrm{I}_{15 / 2}$ and ${ }^{4} \mathrm{~S}_{3 / 2} \rightarrow{ }^{4} \mathrm{I}_{15 / 2}$ transitions, respectively. The integrated ranges for both transitions are 515$540 \mathrm{~nm}$ and $540-570 \mathrm{~nm}$, respectively. $N\left({ }^{2} \mathrm{H}_{11 / 2}\right)$ and $N\left({ }^{4} \mathrm{~S}_{3 / 2}\right)$ are the population numbers of ${ }^{2} \mathrm{H}_{11 / 2}$ and ${ }^{4} \mathrm{~S}_{3 / 2}$ energy levels, respectively. $\Delta E$ is the bandgap between the ${ }^{2} \mathrm{H}_{11 / 2}$ and ${ }^{4} \mathrm{~S}_{3 / 2} . k$ is the Boltzmann constant and $T$ is the absolute temperature.

The correlation between $\ln$ (FIR) and the inverse absolute temperature $1 / T$ is described in Fig. 6(c). The linear fitting of the experimental values $\ln (\mathrm{FIR})$ as a function of the $1 / T$ gives a slope about 1073.76. From this slope, the value of $\Delta E$ is calculated to be approximately $746.2 \mathrm{~cm}^{-1}$, which is very close to the energy gap between the ${ }^{2} \mathrm{H}_{11 / 2}$ and ${ }^{4} \mathrm{~S}_{3 / 2}$ levels calculated from the upconversion emission spectra.

The absolute sensitivity $\left(S_{\mathrm{a}}\right)$ and relative sensitivity $\left(S_{\mathrm{r}}\right)$ are usually used to evaluate the temperature sensing performance and defined as the rate at which the absolute and relative FIR change with the temperature, which could be calculated using the following formula:

$$
\begin{aligned}
& \mathrm{S}_{a}=\left|\frac{\mathrm{dFIR}}{\mathrm{d} T}\right|=\mathrm{FIR} \frac{\Delta E}{k T^{2}} \\
& \mathrm{~S}_{r}=\left|\frac{1}{\mathrm{FIR}} \frac{\mathrm{dFIR}}{\mathrm{d} T}\right|=\frac{\Delta E}{k T^{2}}
\end{aligned}
$$

The corresponding sensitivity curves are demonstrated in Fig. 6(d). Table 1 lists the FIR parameters, relative sensitivity $S_{\mathrm{r}}$, the maximum sensitivity $S_{\mathrm{a}}$ and the temperatures for the maximum sensitivity in different host matrix. Because $S_{\mathrm{r}}$ depends only on the energy gap $\Delta E$, the $S_{\mathrm{r}}$ decreases gradually with the increase of temperature. Furthermore, due to its 

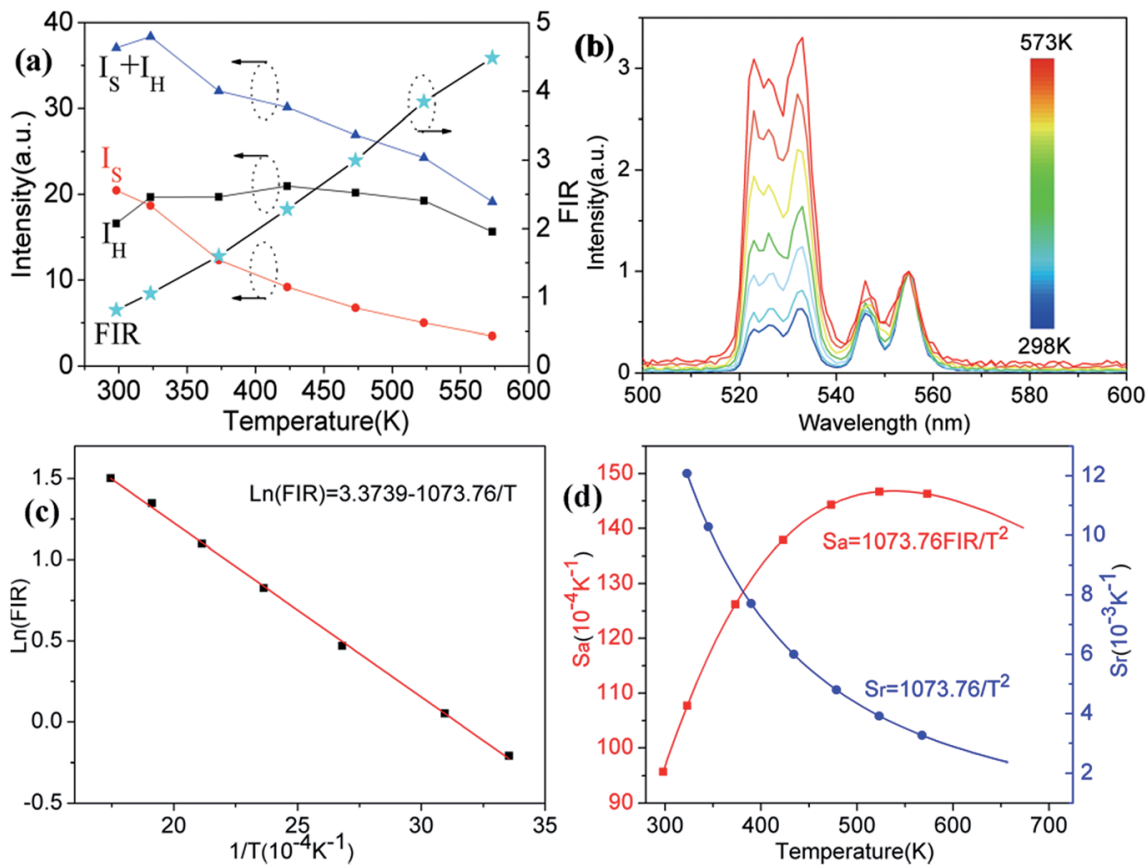

Fig. 6 (a) Integrated upconversion intensities of ${ }^{2} \mathrm{H}_{11 / 2}\left(/_{\mathrm{H}}\right)$ and ${ }^{4} \mathrm{~S}_{3 / 2}\left(/_{\mathrm{S}}\right)$ as well as FIR versus temperature; (b) normalized upconversion luminescence of $\mathrm{Er}^{3+}$ at a temperature range of $298-573 \mathrm{~K}$; (c) $\ln (\mathrm{FIR})$ as a function of the inverse absolute temperature $1 / T$; (d) temperature sensitivity versus absolute temperature.

Table 1 FIR parameters, relative sensitivity $S_{r}$, the maximum sensitivity $S_{a}$ and temperatures in different host matrix

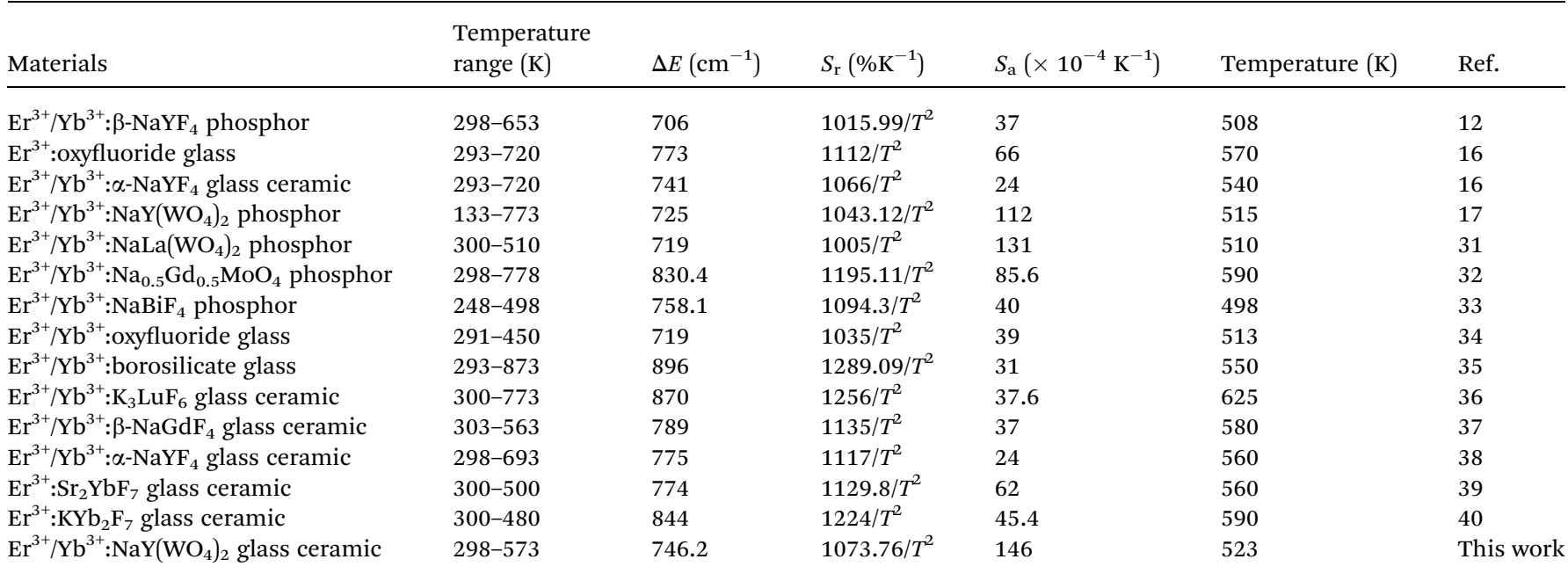

moderate energy gap, $S_{\mathrm{r}}$ achieved here is comparable to most of values of $\mathrm{Er}^{3+}$ ions in other host matrix. The absolute temperature sensitivity $S_{\text {a }}$ increases rapidly with the increase of temperature and achieves the maximum value $146 \times 10^{-4} \mathrm{~K}^{-1}$ at $523 \mathrm{~K}$. Clearly, the temperature sensitivity $S_{\mathrm{a}}$ in our work is much larger than the reported data in fluorides, glass and glass ceramics and slightly larger than the value in tungstates and molybdates. According to Judd-Ofelt theory, S. F. León-Luis proposed that the host matrices with highly distorted local symmetry environments for $\mathrm{Er}^{3+}$ ions could obtain large fluorescence intensity ratios and high temperature sensitivities. ${ }^{\mathbf{1 6}}$ Generally, rare earth ions are situated in a symmetric environment in the fluoride, while rare earth ions are located in the asymmetric surroundings in the double tungstates/molybdates due to its highly disordered structure. ${ }^{41}$ The above spectral analysis of $\mathrm{Sm}^{3+}$ ions in the $\mathrm{NaY}\left(\mathrm{WO}_{4}\right)_{2}$ glass ceramic also confirmed this point. Thus, our experiment provides a new evidence for the viewpoint that the disordered local surroundings around active ions are responsible for the enhancement of the optical sensitivity.

\section{Conclusions}

An optimized glass composition and an appropriate thermal treatment condition leads to the preparation of a novel glass ceramics, composed of $\mathrm{NaY}\left(\mathrm{WO}_{4}\right)_{2}$ nanocrystals dispersed 
homogeously in the amorphous glass matrix. The microstructure of these nanocrystals were analysed in details based on the XRD and TEM data. The influence of thermal treatment temperature on the luminescence of $\mathrm{Sm}^{3+}$ and $\mathrm{Er}^{3+} / \mathrm{Yb}^{3+}$ ions is studied thoroughly. During the devitrification process, $\mathrm{Sm}^{3+}$ and $\mathrm{Er}^{3+} / \mathrm{Yb}^{3+}$ ions are gradually segregated into the precipitated low phonon energy $\mathrm{NaY}\left(\mathrm{WO}_{4}\right)_{2}$ nanocrystals with a high disorder, which results in the enhancement of photoluminescence emission intensity, well-resolved Stark splitting and long luminescence decay lifetimes. According to the dependence of upconversion intensity on the excitation power, the upconversion mechanism of $\mathrm{Er}^{3+}-\mathrm{Yb}^{3+}$ ions was put forward. The temperature sensing performance was investigated based on the FIR technique and a maximum sensitivity $146 \times 10^{-4} \mathrm{~K}^{-1}$ was achieved at $523 \mathrm{~K}$. The established correlation of structure, luminescence and temperature sensing provides a new approach to optimize the best host materials for temperature sensing applications.

\section{Conflicts of interest}

There are no conflicts to declare.

\section{Acknowledgements}

This work was supported by Zhejiang Provincial Natural Science Foundation of China (No LR15F050003, LD18F050001 and LY18E020008), National Natural Science Foundation of China (No 51372236).

\section{Notes and references}

1 Y. F. Wang, G. Y. Liu, L. D. Sun, J. W. Xiao, J. C. Zhou and C. H. Yan, ACS Nano, 2013, 7, 7200-7206.

2 J. C. Goldschmidt and S. Fischer, Adv. Opt. Mater., 2015, 3, 510-535.

3 V. Mahalingam, F. Mangiarini, F. Vetrone, V. Venkatramu, M. Bettinelli, A. Speghini and J. A. Capobianco, J. Phys. Chem. C, 2008, 112, 1774501149.

4 B. Dong, B. S. Cao, Y. Y. He, Z. Liu, Z. P. Li and Z. Q. Feng, Adv. Mater., 2012, 24, 1987-1993.

5 Y. Y. Tian, Y. Tian, P. Huang, L. Wang, Q. F. Shi and C. Cui, Chem. Eng. J., 2016, 297, 26-34.

6 D. Q. Chen, Z. Y. Wan, Y. Zhou, P. Huang, J. S. Zhong, M. Y. Ding, W. D. Xiang, X. J. Liang and Z. G. Ji, J. Alloys Compd., 2015, 638, 21-28.

7 D. Q. Chen, Z. Y. Wan, Y. Zhou, X. Z. Zhou, Y. L. Yu, J. S. Zhong, M. Y. Ding and Z. G. Ji, ACS Appl. Mater. Interfaces, 2015, 7, 19484-19493.

8 L. Mukhopadhyay and V. K. Rai, New J. Chem., 2017, 41, 7650-7661.

9 S. F. León-Luis, U. R. Rodríguez-Mendoza, E. Lalla and V. Lavin, Sens. Actuators, B, 2011, 158, 208-213.

10 X. S. Qiao, X. P. Fan and M. Q. Wang, Appl. Phys. Lett., 2006, 89, 111919.

11 S. L. Zhao, X. Sun, X. L. Wang, L. H. Huang, Y. Fei and S. Q. Xu, J. Eur. Ceram. Soc., 2015, 35, 4225-4231.
12 L. L. Tong, X. P. Li, J. S. Zhang, S. Xu, J. S. Sun, L. H. Cheng, H. Zheng, Y. Q. Zhang, X. Q. Zhang, R. N. Hua, H. P. Xia and B. J. Chen, Sens. Actuators, B, 2017, 246, 175-180.

13 D. Manzani, J. F. S. Petruci, K. Nigoghossian, A. A. Cardoso and S. J. L. Ribeiro, Sci. Rep., 2017, 7, 41596.

14 B. R. Judd, Phys. Rev., 1962, 127, 750-761.

15 G. S. Ofelt, J. Chem. Phys., 1962, 37, 511-520.

16 S. F. León-Luis, U. R. Rodríguez-Mendoza, P. Haro-González and I. R. Martín, Sens. Actuators, B, 2012, 174, 176-186.

17 P. Du, L. H. Luo and J. S. Yu, Ceram. Int., 2016, 42, 56355641.

18 X. S. Qiao, X. P. Fan, J. Wang and M. Q. Wang, J. Appl. Phys., 2006, 99, 074302.

19 J. D. Fan, H. J. Zhang, W. T. Yu, H. H. Yu, J. Y. Wang and M. H. Jiang, J. Appl. Crystallogr., 2008, 41, 584-591.

20 P. Du, X. Y. Huang and J. S. Yu, Inorg. Chem. Front., 2017, 4, 1987-1995.

21 G. Dantelle, M. Mortier, G. Patriarche and D. Vivien, J. Solid State Chem., 2006, 179, 1995-2003.

22 L. L. Wang, B. K. Moon, S. H. Park, J. H. Kim, J. S. Shi, K. H. Kim and J. H. Jeong, RSC Adv., 2015, 5, 8929089298.

23 D. Q. Chen, Y. L. Yu, P. Huang, F. Y. Weng, H. Lin and Y. S. Wang, Appl. Phys. Lett., 2009, 94, 041909.

24 A. C. Yanes, A. Santana-Alonso, J. Mendez-Ramos, J. Castillo and V. D. Rodriguez, Adv. Funct. Mater., 2011, 21, 3136-3142.

25 G. Seeta Rama Raju and S. Buddhudu, Spectrochim. Acta, Part A, 2008, 70, 601-605.

26 D. Li, Y. Wang, X. Zhang, H. Dong, L. Liu, G. Shi and Y. Song, J. Appl. Phys., 2012, 112, 094701.

27 D. G. Yin, C. C. Wang, J. Ouyang, K. L. Song, B. Liu, X. Z. Cao, L. Zhang, Y. L. Han, X. Long and M. H. Wu, Dalton Trans., 2014, 43, 12037-12043.

28 L. Li, X. H. Tang, Z. Q. Jiang, X. J. Zhou, S. Jiang, X. B. Luo, G. T. Xiang and K. N. Zhou, J. Alloys Compd., 2017, 701, 515-523.

29 S. Jiang, P. Zeng, L. Q. Liao, S. F. Tian, H. Guo, Y. H. Chen, C. K. Duan and M. Yin, J. Alloys Compd., 2014, 617, 538-541.

30 M. Pollnau, D. R. Gamelin, S. R. Lüthi, H. U. Güdel and M. P. Hehlen, Phys. Rev. B: Condens. Matter Mater. Phys., 2000, 61, 3337-3346.

31 D. He, C. F. Guo, S. S. Zhou, L. L. Zhang, Z. Yang, C. K. Duan and M. Yin, CrystEngComm, 2015, 17, 7745-7753.

32 P. Du, L. H. Luo, H. K. Park and J. S. Yu, Chem. Eng. J., 2016, 306, 840-848.

33 P. P. Lei, R. An, X. S. Zhai, S. Yao, L. L. Dong, X. Xu, K. M. Du, M. L. Zhang, J. Feng and H. J. Zhang, J. Mater. Chem. C, 2017, 5, 9659-9665.

34 F. Li, B. Y. Lai, J. Wang, G. Q. Du and Q. Su, J. Lumin., 2010, 130, 2418-2423.

35 S. Zhou, C. Li, Z. Liu, S. Li and C. Song, Opt. Mater., 2007, 30, 513-516.

36 J. K. Cao, F. F. Hu, L. P. Chen, H. Guo, C. K. Duan and M. Yin, J. Am. Ceram. Soc., 2017, 100, 2108-2115. 
37 D. Q. Chen, Z. Y. Wan, Y. Zhou, P. Huang, J. S. Zhong, M. Y. Ding, W. D. Xiang, X. J. Liang and Z. G. Ji, J. Alloys Compd., 2015, 638, 21-28.

38 S. Jiang, P. Zeng, L. Q. Liao, S. F. Tian, H. Guo, Y. H. Chen, C. K. Duan and M. Yin, J. Alloys Compd., 2014, 617, 538541.
39 X. M. Li, J. M. Cao, Y. L. Wei, Z. R. Yang and H. Guo, J. Am. Ceram. Soc., 2015, 98, 3824-3830.

40 J. K. Cao, F. F. Hu, L. P. Chen, H. Guo, C. K. Duan and M. Yin, J. Alloys Compd., 2017, 693, 326-331.

41 J. M. Cano-Torres, M. Rico, X. Han, M. D. Serrano, C. Cascales and C. Zaldo, Phys. Rev. B: Condens. Matter Mater. Phys., 2011, 84, 174207. 